\title{
Chemoradiatie bij het spierinvasieve blaascarcinoom
}

\author{
Richard P. Meijer
}

Published online: 27 November 2015

(C) The Author(s) 2015. This article is published with open access at Springerlink.com

Samenvatting Bij steeds meer tumortypen wordt een multimodulaire behandeling toegepast, bestaande uit systeemtherapie (neoadjuvante chemotherapie) gecombineerd met lokale therapie (chirurgie of radiotherapie), om de prognose te verbeteren. Voor patiënten met een spierinvasief blaascarcinoom, biedt een multimodulaire therapie middels transurethrale tumorresectie, gevolgd door chemoradiatie, een blaassparende behandelmogelijkheid. Door deze behandeling zal een aanzienlijke groep ook op langere termijn een goede ziektevrije overleving hebben, een goede blaasfunctie behouden en slechts beperkte gastro-intestinale klachten ervaren. Echter, een nauwgezette follow-up met beeldvorming en cystoscopie zal nodig zijn om eventuele recidiefziekte tijdig op te sporen en te kunnen behandelen.

Trefwoorden blaascarcinoom - multimodulaire behandeling . chemoradiatie

\section{Chemoradiation for muscle invasive bladder cancer}

Summary The combination of varying treatment strategies (e.g. neoadjuvant chemotherapy and surgery or radiotherapy) in a multimodal setting are increasingly being used in various tumour types. For patients with muscle invasive bladder cancer, multimodal therapy consisting of transurethral resection followed by chemoradiation offers

Een deel van de introductie van dit artikel is eerder verschenen in het proefschrift getiteld: High risk bladder cancer: staging, risk assessment and treatment options. Richard P. Meijer, 2014.

dr. R.P. Meijer $(\bowtie)$

Afdeling Urologische Oncologie,

Universitair Medisch Centrum Utrecht Cancer Center,

Utrecht, Nederland

e-mail: rmeijer6@umcutrecht.nl a bladder preserving treatment option. This treatment will result in good long term recurrence free survival, acceptable bladder function, and minimal gastro-intestinal toxicity. Nevertheless, a strict follow-up schedule with imaging and cystoscopy is required in order to detect local recurrence in time for salvage treatment.

Keywords bladder cancer $\cdot$ multimodal therapy $\cdot$ chemoradiation

\section{Introductie}

Het spierinvasieve blaascarcinoom is een agressieve ziekte die, ondanks ingrijpende en tijdige behandeling vaak resulteert in een matige prognose. De gerapporteerde vijfjaarsoverleving van de huidige standaardtherapie (bilaterale pelviene lymfeklierdissectie (ePLND) en radicale cystectomie) varieert van 36-62\% [1-4]. Voor patiënten met lymfogene metastasen $(\mathrm{N}+)$ of lokaalgevorderde ziekte (T3-T4) is de prognose nog slechter, met een vijfjaarsoverleving van 26-38\% [3, 5]. Bij de patiënten met een lokaal gevorderd blaascarcinoom heeft deze matige prognose waarschijnlijk te maken met een onderstadiëring van de lymfeklierstatus en/of met occulte micrometastasen op het moment van de diagnose [6]. Bij ongeveer $34 \%$ van de patiënten met een klinisch lymfekliernegatief (cN0) lokaal gevorderd blaascarcinoom (T3-T4), wordt bij chirurgie uiteindelijk toch lymfekliermetastasering vastgesteld [7]. Ook de klinische stadiëring na neoadjuvante chemotherapie blijkt slechts een matige betrouwbaarheid te hebben. In een recente serie vanuit het NKI-AVL bleek bij complete responders na chemotherapie bij 37,5\% nog sprake van resttumor bij uiteindelijke chirurgie (negatief voorspellende waarde 62,5\%) [8]. 
Tabel 1 Studies naar chemoradiatie [34]

\begin{tabular}{|c|c|c|c|c|c|c|c|}
\hline \multirow[t]{2}{*}[++]{ studie } & \multirow[t]{2}{*}{$n$} & \multirow[t]{2}{*}{ behandelmodaliteiten } & \multirow{2}{*}{$\begin{array}{l}\text { mediane } \\
\text { FU (mnd) }\end{array}$} & \multirow[t]{2}{*}{ CR (\%) } & \multirow[t]{2}{*}{ OS } & \multicolumn{2}{|c|}{ lokaal recidief na $\mathrm{CR}(\%)$} \\
\hline & & & & & & niet-invasief & invasief \\
\hline [-]RTOG 85-12 [21] & 42 & TURT; CRT (Cis) & 36 & 66 & $64 \%(3 \mathrm{jr})$ & 14 & 25 \\
\hline$[+]$ RTOG $88-02$ [22] & 91 & TURT; MCV; CRT (Cis) & 46 & 68 & $62 \%(4 \mathrm{jr})$ & 26 & 24 \\
\hline [-]RTOG 89-03 [23] & 123 & TURT; MCV; CRT (Cis) & 61 & 59 & $49 \%(5 \mathrm{jr})$ & 28 & 15 \\
\hline [+]RTOG 95-06 [24] & 34 & TURT; CRT (5-FU) & 29 & 67 & $83 \%(3 \mathrm{jr})$ & 30 & 15 \\
\hline [-]RTOG 97-06 [25] & 52 & TURT; CRT (Cis) & 26 & 74 & $61 \%(3 \mathrm{jr})$ & 13 & 6 \\
\hline [+]RTOG 99-06 [26] & 80 & TURT; CRT (Pac/Cis); Gem/Cis & 49 & 81 & $56 \%(5 \mathrm{jr})$ & 11 & 12 \\
\hline$[-] M G H[27]$ & 348 & verschillende behandelschema's ${ }^{\mathrm{a}}$ & 348 & 72 & $52 \%(5 \mathrm{jr})$ & 29 & 16 \\
\hline$[+] B C 2001^{\mathrm{b}},[28]$ & 182 & TURT; \pm NAC (Cis); CRT (5-FU/MMC) & 70 & onbekend & $48 \%(5 \mathrm{jr})$ & 14 & 11 \\
\hline
\end{tabular}

RTOG Radiation Therapy Oncology Group, $M G H$ Massachusetts General Hospital, $F U$ follow-up, $C R$ complete respons, $O S$ overall survival, TURT transurethrale resectie blaastumor, CRT chemoradiatie, Cis cisplatine, 5-FU fluorouracil, Pac paclitaxel, Gem gemcitabine, $M C V$ methotrexaat/cisplatine/vinblastine, $N A C$ (Cis) cisplatinebevattende neoadjuvante chemotherapie, $M M C$ mitomycine C

${ }^{a} \mathrm{MGH}$-protocollen bestonden uit verschillende behandelmodaliteiten: TURT + CRT (Cis) met of zonder (neo)adjuvante chemotherapie

${ }^{\mathrm{b}}$ Alleen de chemoradiatie-arm is hier weergegeven. Tabel aangepast op basis van Oh et al. [34]

\section{Multimodulaire behandeling}

\section{Neoadjuvante chemotherapie en chirurgie}

De ontwikkeling van multimodulaire behandelstrategieën, zoals de toevoeging van neoadjuvante cisplatinebevattende combinatiechemotherapie voorafgaand aan chirurgie, heeft geleid tot een verbetering van de prognose, met name bij patiënten met een lokaal gevorderd spierinvasief blaascarcinoom, alhoewel de literatuur slechts een toename van $6,5 \%$ in overall survival beschrijft na vijfjaar follow-up [9-14].

Het is gebleken dat de uiteindelijke respons op neoadjuvante chemotherapie een belangrijke voorspellende factor is, aangezien patiënten met downstaging tot een niet-spierinvasief stadium $(<$ ypT2N0) en patiënten met complete pathologische respons (ypT0N0) een betere prognose hebben met een vijfjaarsoverleving van $69 \%$ vs. een vijfjaarsoverleving van $26 \%$ van patiënten met persisterend spierinvasief blaascarcinoom [15-19]. Desalniettemin is weinig bekend over de prognostische impact van persisterende lymfekliermetastasen na inductiechemotherapie, alhoewel deze situatie zeer waarschijnlijk gepaard gaat met een infauste prognose [20].

\section{Consoliderende lokale therapie}

Aangezien bij één op de drie patiënten met een radiologisch complete respons toch nog sprake blijkt te zijn van residuele ziekte na neoadjuvante chemotherapie bestaat er zeker een indicatie voor een lokale consoliderende behandeling [8]. Momenteel is chirurgie de standaard behandelkeuze voor lokale controle, een behandeling die met name effectief is gebleken voor een lokaal beperkte resttumor. Patiënten met klinisch lymfeklierpositieve ziekte na inductiechemotherapie $(\mathrm{ycN}+)$ blijken een significant slechtere prognose te hebben dan patiënten met een klinisch lymfekliernega- tieve status (ycN0). Hetzelfde geldt voor de pathologische lymfeklierstatus [20]. Alhoewel chirurgie van belang kan zijn voor adequate stadiëring en daarmee de prognose, is onduidelijk wat de meerwaarde van chirurgie is bij lymfeklierpositieve ziekte na inductiechemotherapie. De rol van consoliderende lokale therapie bij deze patiëntengroep zal nog verder verhelderd moeten worden.

\section{Chemotherapie en radiotherapie}

Naast de combinatie van chemotherapie met radicale chirurgie (cystectomie) is de afgelopen jaren ook steeds meer aandacht voor een combinatie van chemotherapie met radiotherapie, sequentieel of gelijktijdig. Een overzicht van chemoradiatiestudies bij blaaskanker is weergegeven in tab. 1; [21-28]. Een belangrijk voordeel van deze combinatie is het blaassparende karakter ervan. Met name in Groot-Brittannië heeft men veel ervaring opgedaan met deze behandeling [28]. De behandeling van blaaskanker met radiotherapie is in Nederland de afgelopen jaren met name voorbehouden geweest aan oudere patiënten met veel comorbiditeit, bij wie een grote operatie niet haalbaar zou zijn. Echter, door de verbeterde radiotherapeutische technieken en beter inzicht in de behandeling met chemotherapie kan een dergelijke multimodulaire behandeling met chemotherapie en radiotherapie wellicht ook toepasbaar zijn bij patiënten bij wie nu standaard voor een radicale cystectomie met urinedeviatie wordt gekozen. Daarnaast zullen patiënten het vooruitzicht van een blaassparende therapie over het algemeen aantrekkelijk vinden. James et al. beschrijven een multicenter fase 3-studie waarin 360 patiënten met spierinvasief blaascarcinoom werden gerandomiseerd tussen uitwendige radiotherapie met of zonder gelijktijdige chemotherapie [28]. De onderliggende hypothese is dat de chemotherapie als radiosensitizer fungeert, waardoor de effectiviteit van de uitwendige radiotherapie significant wordt vergroot [29]. 
Als radiosensitizer werd door James et al. gebruikgemaakt van een combinatie van 5-fluorouracil en mitomycine-C. In deze studie waren twee radiotherapieschema's toegestaan: 55 Gy in 20 fracties in vier weken of 64 Gy in 32 fracties in 6,5 weken. De locoregionale ziektevrije overleving was significant beter in de chemoradiatiegroep dan in de radiotherapiegroep met een tweejaars-recidiefvrije overleving van $67 \%$ bij chemoradiatie en $54 \%$ bij radiotherapie. De vijfjaars-overall survival bij chemoradiatie was $48 v s$. $35 \%$ bij radiotherapie, een niet-statistisch significant verschil [28]. De conclusie luidde dat de toevoeging van een radiosensitizer zoals 5-fluorouracil en mitomycine-C bij de chemoradiatie met name meerwaarde heeft voor een betere lokale controle en geen evidente invloed heeft op systemische ziekte [28, 30].

In het kader van blaassparende therapie is door Efstathiou et al. een serie van 348 patiënten met spierinvasief blaascarcinoom (cT2-4a) beschreven, bij wie een trimodulaire behandeling werd toegepast, bestaande uit een maximale transurethrale resectie van de blaastumor (TURT) gevolgd door chemoradiatie (cisplatinebevattende chemotherapie en gelijktijdige uitwendige radiotherapie) [27]. In deze studie werd na 40 Gy radiotherapie een controleblaasbiopsie verricht voor responsevaluatie. Bij $72 \%$ van de patiënten bleek sprake van een complete respons en werd verder behandeld met consoliderende chemoradiatie $(25,2$ Gy met een aanvullende cisplatinekuur). Uiteindelijk werd bij 102 patiënten $(29 \%)$ toch een cystectomie verricht; bij $17 \%$ direct omdat geen complete respons werd bereikt en bij $12 \%$ een salvagecystectomie vanwege een recidief invasief blaascarcinoom. De vijfjaars-kankerspecifieke overleving was $64 \%$ ( $74 \%$ voor T2; $53 \%$ voor T3-T4). Een van de belangrijkste voorwaarden voor een dergelijke blaassparende strategie is een intensieve cystoscopische follow-up, zodat in het geval van een lokaal recidief in de blaas, tijdig kan worden overgegaan tot een salvagebehandeling [27]. Tab. 2 toont een mogelijk follow-upschema voor de controles na chemoradiatie [31]. Uit deze studie bleek verder dat het verrichten van een macroscopisch radicale TURT een belangrijke prognostische factor is. In het geval van een complete TURT bleek $79 \%$ van de patiënten een complete respons op de inductiechemotherapie te bereiken $v$ s. $57 \%$ van de patiënten met een macroscopisch incomplete TURT $(p<0,001)$. Daarnaast was bij de patiënten met een complete TURT in $22 \%$ van de gevallen uiteindelijk een cystectomie noodzakelijk, terwijl dit bij $42 \%$ van de patiënten met een incomplete TURT $(p<0,001)$ het geval was [27].

\section{Salvage cystectomie na (chemo)radiotherapie}

In het geval van een niet-spierinvasief recidief blaascarcinoom na (chemo)radiotherapie kan besloten worden tot
Tabel 2 Follow-up na chemoradiatie van de blaas [31]

\begin{tabular}{lccccccccc}
\hline & \multicolumn{1}{c}{ maanden na chemoradiatie } \\
\cline { 2 - 9 } & 3 & 6 & 9 & 12 & 18 & 24 & 36 & 48 & 60 \\
\hline CT thorax-abdomen & $\mathrm{x}$ & $\mathrm{x}$ & & $\mathrm{x}$ & $\mathrm{x}$ & $\mathrm{x}$ & $\mathrm{x}$ & $\mathrm{x}$ & $\mathrm{x}$ \\
Lab $^{\mathrm{a}}$ & $\mathrm{x}$ & $\mathrm{x}$ & $\mathrm{x}$ & $\mathrm{x}$ & $\mathrm{x}$ & $\mathrm{x}$ & $\mathrm{x}$ & $\mathrm{x}$ & $\mathrm{x}$ \\
cystoscopie & $\mathrm{x}$ & $\mathrm{x}$ & $\mathrm{x}$ & $\mathrm{x}$ & $\mathrm{x}$ & $\mathrm{x}$ & $\mathrm{x}$ & $\mathrm{x}$ & $\mathrm{x}$
\end{tabular}

${ }^{a}$ Laboratoriumonderzoek (inclusief hemoglobine, hematocriet, creatinine en alkalisch fosfatase)

lokale therapie middels blaasinstillaties met bijvoorbeeld mitomycine $\mathrm{C}$ of $\mathrm{BCG}$ [32-35]. Wanneer echter na chemoradiatie sprake blijkt te zijn van een spierinvasief recidief, zal besloten moeten worden tot een salvagecystectomie. Deze salvagechirurgie gaat mogelijk gepaard met een wat groter complicatierisico dan een primaire cystectomie [36-38]. In een serie van Eisenberg et al. worden de uitkomsten geëvalueerd van 148 patiënten die een salvagecystectomie hebben ondergaan na een hoge dosis uitwendige radiotherapie op de bekkenregio. Hierbij hebben zij gestandaardiseerd gebruikgemaakt van het Clavien-Dindo-systeem om vroege ( $<90$ dagen) en late ( $>90$ dagen) complicaties te registreren. Vergeleken met de literatuur was het complicatierisico in deze serie hoog $(77 \%)$, waarbij met name gastro-intestinale complicaties $(30,7 \%)$ het meest frequent voorkwamen, gevolgd door infectieuze $(15,2 \%)$ en bloedingscomplicaties $(9,9 \%)$.

Eswara et al. beschrijven een serie van 91 patiënten, die na aanvankelijke multimodulaire therapie (TURT, uitwendige radiotherapie en chemotherapie) alsnog een salvagecystecomie ondergingen [38]. Zij maakten onderscheid tussen patiënten die een 'immediate' salvagecystectomie ondergingen vanwege incomplete respons na inductiechemoradiatie $(n=51 ; 56 \%)$ en patiënten die een 'delayed" salvagecystectomie ondergingen vanwege een recidief T1-4-blaascarcinoom, dat werd gevonden tijdens followup $(n=40 ; 44 \%)$. Bij de immediate cystectomiegroep werden significant meer cardiovasculaire en hematologische complicaties binnen 90 dagen vastgesteld (inclusief longembolie, myocardinfarct, diepveneuze trombose en anemie. Daarentegen werden in de delayed cystectomiegroep significant meer wondgenezingsproblemen gezien, zoals fasciedehiscentie, wondinfectie, ureterstricturen, anastomosestricturen en stomacomplicaties, waarvoor revisie werd verricht. Deze complicaties kwamen bijna driemaal vaker voor in de delayed cystectomiegroep dan in de andere groep [38].

In tegenstelling tot de eerder genoemde series, is door Ramani et al. een grote single-centerserie gepubliceerd waarin geen verschillen werden gevonden in perioperatieve mortaliteit tussen primaire cystectomie $(n=426) v s$. salvagecystectomie na uitwendige bestraling op het bekken $(n=420)$. Ook werden tussen beide groepen geen sig- 
nificante verschillen gevonden in complicaties, behoudens een hoger percentage stomaproblematiek (stenosering) in de bestraalde groep [39]. Ook andere series tonen geen hogere postoperatieve risico's bij salvagecystectomie; het type urinedeviatie bij patiënten met status na bekkenbestraling heeft evenmin invloed op de postoperatieve risico's $[36,40]$.

\section{Toxiciteit na chemoradiatie en kwaliteit van leven}

Naast het oncologische doel heeft een blaassparende behandeling uiteraard ook een adequate functionele uitkomst als doel. Dat betekent dat eventuele toxiciteit van de behandeling goed moet worden geregistreerd en dat late toxiciteit beperkt moet blijven. De kwaliteit van leven na chemoradiatie vanwege invasief blaascarcinoom op de langere termijn werd door Zietman et al. gerapporteerd van twee groepen. De ene groep bestond uit patiënten $(n=49)$ die een trimodulaire blaassparende therapie hadden ondergaan (maximale transurethrale resectie van de blaastumor gevolgd door chemoradiatie) en de andere groep bestond uit patiënten met een intacte blaas, na een mediane follow-up van 6,3 jaar [41]. Bij urodynamisch onderzoek bleek bij $75 \%$ van de patiënten sprake van een adequaat functionerende blaas. Een afname in blaaswandcompliantie werd gezien bij $22 \%$ van de patiënten, echter, bij slechts één op de drie patiënten leidde deze afname tot irritatieve mictieklachten. Verder werd bij één op de vijf patiënten (22\%) gastro-intestinale symptomen gerapporteerd, hetgeen $14 \%$ van de patiënten als klachten classificeerde.

Efstathiou et al. beschrijven de follow-up op de langere termijn van patiënten $(n=157)$ die werden behandeld met chemoradiatie vanwege een spierinvasief blaascarcinoom, waarbij geselecteerd werd op een minimale overleving van twee jaar met intacte blaas [42]. De mediane follow-up in deze groep was 5,4 jaar (range 2-13). Late graad 3-toxiciteit werd vermeld bij 11 patiënten $(7 \%)$, van wie negen patiënten $(5,7 \%)$ met irritatieve mictieklachten (urgency, frequency of hematurie) en drie patiënten (1,9\%) met gastro-intestinale klachten (sigmoïdobstructie, proctitis). De mediane termijn tot het ontwikkelen van late graad 3-toxiciteit was 22 maanden. De mediane duur van de mictieklachten was 7,1 maanden (range 4-33) voordat de ernst van de klachten afnam. Hiermee kan gesteld worden dat de late toxiciteit van chemoradiatie bij het blaascarcinoom beperkt is en dat veel patiënten na twee jaar follow-up hun eigen blaas nog konden behouden [30].

\section{Conclusies}

Concluderend kan gesteld worden dat voor het spierinvasieve blaascarcinoom, de cystectomie met urinedeviatie vooralsnog de 'gouden standaard' blijft. Echter, bij een geselecteerde patiëntengroep met een spierinvasief blaascarcinoom, kan een multimodulaire blaassparende behandeling tot de mogelijkheden behoren. Daarbij zal een aanzienlijke groep ook op langere termijn een goede ziektevrije overleving hebben, een goede blaasfunctie behouden en slechts beperkte gastro-intestinale klachten ervaren. Echter, een nauwgezette follow-up met beeldvorming en cystoscopie zal nodig zijn om eventuele recidiefziekte tijdig op te sporen en te kunnen behandelen.

Open Access This article is distributed under the terms of the Creative Commons Attribution 4.0 International License (http://creativecommons.org/licenses/by/4.0/), which permits unrestricted use, distribution, and reproduction in any medium, provided you give appropriate credit to the original author(s) and the source, provide a link to the Creative Commons license, and indicate if changes were made.

\section{Literatuur}

1. Ghoneim MA, el-Mekresh MM, el-Baz MA, et al. Radical cystectomy for carcinoma of the bladder: critical evaluation of the results in 1,026 cases. J Urol. 1997;158(2):393-9.

2. Dalbagni G, Genega E, Hashibe M, et al. Cystectomy for bladder cancer: a contemporary series. J Urol. 2001;165(4):1111-6.

3. Madersbacher S, Hochreiter W, Burkhard F, et al. Radical cystectomy for bladder cancer today - a homogeneous series without neoadjuvant therapy. J Clin Oncol. 2003;21(4):690-6.

4. Stein JP, Lieskovsky G, Cote R, et al. Radical cystectomy in the treatment of invasive bladder cancer: long-term results in 1,054 patients. J Clin Oncol. 2001;19(3):666-75.

5. Herr HW, Donat SM. Outcome of patients with grossly node positive bladder cancer after pelvic lymph node dissection and radical cystectomy. J Urol. 2001;165(1):62-4. (discussion 4).

6. Vries RR de, Nieuwenhuijzen JA, Meinhardt W, et al. Long-term survival after combined modality treatment in metastatic bladder cancer patients presenting with supra-regional tumor positive lymph nodes only. Eur J Surg Oncol. 2009;35(4):352-5.

7. Dhar NB, Klein EA, Reuther AM, et al. Outcome after radical cystectomy with limited or extended pelvic lymph node dissection. $\mathrm{J}$ Urol. 2008;179(3):873-8. (discussion 8).

8. Meijer RP, Nieuwenhuijzen JA, Meinhardt W, et al. Response to induction chemotherapy and surgery in non-organ confined bladder cancer: a single institution experience. Eur J Surg Oncol. 2013;39(4):365-71.

9. Winquist E, Kirchner TS, Segal R, et al. Neoadjuvant chemotherapy for transitional cell carcinoma of the bladder: a systematic review and meta-analysis. J Urol. 2004;171(2 Pt 1):561-9.

10. International collaboration of trialists. Neoadjuvant cisplatin, methotrexate, and vinblastine chemotherapy for muscleinvasive bladder cancer: a randomised controlled trial. Lancet. 1999;354(9178):533-40.

11. Sherif A, Rintala E, Mestad O, et al. Neoadjuvant cisplatin-methotrexate chemotherapy for invasive bladder cancer - Nordic cystectomy trial 2. Scand J Urol Nephrol. 2002;36(6):419-25.

12. Advanced Bladder Cancer (ABC) Meta-analysis Collaboration. Neoadjuvant chemotherapy in invasive bladder cancer: update of a systematic review and meta-analysis of individual patient data advanced bladder cancer (ABC) meta-analysis collaboration. Eur Urol. 2005;48(2):202-5. (discussion 5-6). 
13. Hall RR. Updated results of a randomised controlled trial of neoadjuvant cisplatin (C), methotrexate (M) and vinblastine (V) chemotherapy for muscle-invasive bladder cancer. Proc Am Soc Clin Oncol. 2001; 21 (abstr 710).

14. Griffiths G, Hall R, Sylvester R, et al. International phase III trial assessing neoadjuvant cisplatin, methotrexate, and vinblastine chemotherapy for muscle-invasive bladder cancer: long-term results of the BA06 30894 trial. J Clin Oncol. 2011;29(16):2171-7.

15. Teramukai S, Nishiyama H, Matsui Y, et al. Evaluation for surrogacy of end points by using data from observational studies: tumor downstaging for evaluating neoadjuvant chemotherapy in invasive bladder cancer. Clin Cancer Res. 2006;12(1):139-43.

16. Splinter TA, Pavone-Macaluso M, Jacqmin D, et al. A European Organization for Research and Treatment of Cancer - Genitourinary Group phase 2 study of chemotherapy in stage T3-4N0-XM0 transitional cell cancer of the bladder: evaluation of clinical response. J Urol. 1992;148(6):1793-6.

17. Millikan R, Dinney C, Swanson D, et al. Integrated therapy for locally advanced bladder cancer: final report of a randomized trial of cystectomy plus adjuvant M-VAC versus cystectomy with both preoperative and postoperative M-VAC. J Clin Oncol. 2001;19(20):4005-13.

18. Sternberg CN, Pansadoro V, Calabro F, et al. Can patient selection for bladder preservation be based on response to chemotherapy? Cancer. 2003;97(7):1644-52.

19. Rosenblatt R, Sherif A, Rintala E, et al. Pathologic downstaging is a surrogate marker for efficacy and increased survival following neoadjuvant chemotherapy and radical cystectomy for muscleinvasive urothelial bladder cancer. Eur Urol. 2012;61(6):1229-38.

20. Meijer RP, Mertens LS, Rhijn BW van, et al. Induction chemotherapy followed by surgery in node positive bladder cancer. Urology. 2014;83(1):134-9

21. Tester W, Porter A, Asbell S, et al. Combined modality program with possible organ preservation for invasive bladder carcinoma: results of RTOG protocol 85-12. Int J Radiat Oncol Biol Phys. 1993;25(5):783-90.

22. Tester W, Caplan R, Heaney J, et al. Neoadjuvant combined modality program with selective organ preservation for invasive bladder cancer: results of Radiation Therapy Oncology Group phase II trial 8802. J Clin Oncol. 1996;14(1):119-26.

23. Shipley WU, Winter KA, Kaufman DS, et al. Phase III trial of neoadjuvant chemotherapy in patients with invasive bladder cancer treated with selective bladder preservation by combined radiation therapy and chemotherapy: initial results of Radiation Therapy Oncology Group 89-03. J Clin Oncol. 1998;16(11):3576-83.

24. Kaufman DS, Winter KA, Shipley WU, et al. The initial results in muscle-invading bladder cancer of RTOG 95-06: phase I/II trial of transurethral surgery plus radiation therapy with concurrent cisplatin and 5-fluorouracil followed by selective bladder preservation or cystectomy depending on the initial response. Oncologist. 2000;5(6):471-6.

25. Hagan MP, Winter KA, Kaufman DS, et al. RTOG 97-06: initial report of a phase I-II trial of selective bladder conservation using TURBT, twice-daily accelerated irradiation sensitized with cisplatin, and adjuvant MCV combination chemotherapy. Int J Radiat Oncol Biol Phys. 2003;57(3):665-72.

26. Kaufman DS, Winter KA, Shipley WU, et al. Phase I-II RTOG study (99-06) of patients with muscle-invasive bladder cancer undergoing transurethral surgery, paclitaxel, cisplatin, and twice-daily radiotherapy followed by selective bladder preservation or radical cystectomy and adjuvant chemotherapy. Urology. 2009;73(4):833-7.
27. Efstathiou JA, Spiegel DY, Shipley WU, et al. Long-term outcomes of selective bladder preservation by combined-modality therapy for invasive bladder cancer: the MGH experience. Eur Urol. 2012;61(4):705-11.

28. James ND, Hussain SA, Hall E, et al. Radiotherapy with or without chemotherapy in muscle-invasive bladder cancer. N Engl J Med. 2012;366(16):1477-88.

29. Coppin CM, Gospodarowicz MK, James K, et al. Improved local control of invasive bladder cancer by concurrent cisplatin and preoperative or definitive radiation. The National Cancer Institute of Canada Clinical Trials Group. J Clin Oncol. 1996;14(11):2901-7.

30. Gakis G, Efstathiou J, Lerner SP, et al. ICUD-EAU International Consultation on Bladder Cancer 2012: radical cystectomy and bladder preservation for muscle-invasive urothelial carcinoma of the bladder. Eur Urol. 2013;63(1):45-57.

31. Stenzl A, Cowan NC, De Santis M, et al. The updated EAU guidelines on muscle-invasive and metastatic bladder cancer. Eur Urol. 2009;55(4):815-25.

32. Shipley WU, Kaufman DS, Zehr E, et al. Selective bladder preservation by combined modality protocol treatment: long-term outcomes of 190 patients with invasive bladder cancer. Urology. 2002;60(1):62-7. (discussion 7-8).

33. Weiss C, Wittlinger M, Engehausen DG, et al. Management of superficial recurrences in an irradiated bladder after combinedmodality organ-preserving therapy. Int J Radiat Oncol Biol Phys. 2008;70(5):1502-6.

34. Oh KS, Soto DE, Smith DC, et al. Combined-modality therapy with gemcitabine and radiation therapy as a bladder preservation strategy: long-term results of a phase I trial. Int J Radiat Oncol Biol Phys. 2009;74(2):511-7.

35. Meijer RP, Meinhardt W, Poel HG van der, et al. Local control rate and prognosis after sequential chemoradiation for small cell carcinoma of the bladder. Int J Urol. 2013.Aug;20(8):778-84.

36. Hautmann RE, de Petriconi R, Volkmer BG. Neobladder formation after pelvic irradiation. World J Urol. 2009;27(1):57-62.

37. Eisenberg MS, Dorin RP, Bartsch G, et al. Early complications of cystectomy after high dose pelvic radiation. J Urol. 2010;184(6):2264-9.

38. Eswara JR, Efstathiou JA, Heney NM, et al. Complications and long-term results of salvage cystectomy after failed bladder sparing therapy for muscle invasive bladder cancer. J Urol. 2012;187(2):463-8.

39. Ramani VA, Maddineni SB, Grey BR, Clarke NW. Differential complication rates following radical cystectomy in the irradiated and nonirradiated pelvis. Eur Urol. 2010;57(6):1058-63.

40. Nieuwenhuijzen JA, Vries RR de, Bex A, et al. Urinary diversions after cystectomy: the association of clinical factors, complications and functional results of four different diversions. Eur Urol. 2008;53(4):834-42. (discussion 42-4).

41. Zietman AL, Sacco D, Skowronski U, et al. Organ conservation in invasive bladder cancer by transurethral resection, chemotherapy and radiation: results of a urodynamic and quality of life study on long-term survivors. J Urol. 2003;170(5):1772-6.

42. Efstathiou JA, Bae K, Shipley WU, et al. Late pelvic toxicity after bladder-sparing therapy in patients with invasive bladder cancer: RTOG 89-03, 95-06, 97-06, 99-06. J Clin Oncol. 2009;27(25):4055-61.

dr. Richard P. Meijer, uroloog. 